\title{
A Requirement for the rac1 GTPase in the Signal Transduction Pathway Leading to Cardiac Myocyte Hypertrophy
}

\author{
John B. Pracyk,, Koichi Tanaka, ${ }^{*}$ Donald D. Hegland," Kyung-Soo Kim, ${ }^{\star}$ Rachna Sethi," Ilsa I. Rovira, ${ }^{\star}$ David R. Blazina, \\ Larisse Lee, ${ }^{\star}$ Joseph T. Bruder, ${ }^{\ddagger}$ Imre Kovesdi, ${ }^{\ddagger}$ Pascal J. Goldshmidt-Clermont, ${ }^{\S}$ Kaikobad Irani,,$\|$ and Toren Finkel ${ }^{\star}$ \\ *Cardiology Branch, National Heart, Lung, and Blood Institute, National Institutes of Health, Bethesda, Maryland 20892; ${ }^{\ddagger}$ Genvec, Inc., \\ Rockville, Maryland 20852; ${ }^{\circledR}$ Heart and Lung Institute, Ohio State University, Columbus, Ohio 43210; and $\|_{\text {Cardiology Division, Johns }}$ \\ Hopkins Medical School, Baltimore, Maryland 21205
}

\begin{abstract}
We have used adenoviral-mediated gene transfer of a constitutively active (V12rac1) and dominant negative (N17rac1) isoform of rac1 to assess the role of this small GTPase in cardiac myocyte hypertrophy. Expression of V12rac1 in neonatal cardiac myocytes results in sarcomeric reorganization and an increase in cell size that is indistinguishable from ligand-stimulated hypertrophy. In addition, V12rac1 expression leads to an increase in atrial natriuretic peptide secretion. In contrast, expression of N17rac1, but not a truncated form of Raf-1, attenuated the morphological hypertrophy associated with phenylephrine stimulation. Consistent with the observed effects on morphology, expression of V12rac1 resulted in an increase in new protein synthesis, while N17rac1 expression inhibited phenylephrine-induced leucine incorporation. These results suggest rac1 is an essential element of the signaling pathway leading to cardiac myocyte hypertrophy. (J. Clin. Invest. 1998. 102:929-937.) Key words: GTPase $\bullet$ rac1 $\bullet$ myocyte $\bullet$ hypertrophy $\bullet$ signal transduction
\end{abstract}

\section{Introduction}

Hypertrophy of the ventricular myocardium represents not only a physiological response to increased workloads, but also an adaptive response to cardiac failure. Epidemiological evidence suggests that $\sim 15-20 \%$ of adults in the United States demonstrate some echocardiographic evidence of left ventricular hypertrophy (1). Studies suggest that such hypertrophy is an independent risk factor for cardiac morbidity and results in approximately a twofold increase in the relative risk of mortality from cardiovascular disease (2).

Analysis of the signal transduction cascade regulating cardiac hypertrophy has, in general, used neonatal ventricular myocytes as a model system. Studies of these cells in culture have revealed that stimulation with a mechanical stress as well as with either phenylephrine, angiotensin II, endothelin-1, acidic or basic fibroblast growth factor, or leukemia inhibitory

Address correspondence to Toren Finkel, M.D., Ph.D., Cardiology Branch, NHLBI-NIH, 10 Center Drive, MSC 1650, Building 10, Room 7B-15, Bethesda, MD 20892. Phone: 301-402-4081; FAX: 301402-0888; E-mail: finkelt@gwgate.nhlbi.nih.gov

Received for publication 17 December 1997 and accepted in revised form 17 June 1998.

The Journal of Clinical Investigation

Volume 102, Number 5, September 1998, 929-937

http://www.jci.org factor, results in the induction of the hypertrophic program (reviewed in refs. 3, 4).

On a cellular level, hypertrophy is characterized by morphological changes including an increase in cell size and the reorganization of actin fibers into distinct sarcomeric structures. Hypertrophic pharmacologic stimuli also result in the activation of immediate early genes (e.g., c-fos, c-jun, erg-1), reactivation of fetal genes (e.g., atrial natriuretic peptide [ANP], $\beta$-myosin heavy chain and skeletal muscle $\alpha$-actin) as well as an increase in the level of certain constitutively expressed contractile elements (e.g., myosin light chain-2 and cardiac $\alpha$-actin) $(3,4)$. Given that a variety of diverse stimulants can trigger a similar pattern of cellular hypertrophy, it is reasonable to speculate that there might be a final common, shared intracellular pathway.

Previous studies have demonstrated that microinjection of a constitutively active form of the small GTP-binding protein ras results in an increase in cell surface area, organizes the contractile apparatus (sarcomerogenesis), and enhances expression of specific hypertrophic gene products such as ANP (5). In addition, ligands that induce hypertrophy appear to activate a host of ras-dependent pathways $(6,7)$. The downstream effector(s) of ras that regulate myocyte hypertrophy have, however, remained incompletely characterized. Studies in other cell types have demonstrated that ras can directly associate with the Raf- 1 kinase $(8,9)$ and subsequently induce the activation of the mitogen-activated protein kinase (MAPK) (reviewed in ref. 10). As such, several studies have explored the role of Raf-1 and MAPK in myocyte hypertrophy. Some studies using transient transfection of dominant negative forms of Raf-1 or MAPK have seen no effects on sarcomeric organization $(11,12)$ while others using antisense oligonucleotides to decrease MAPK protein have shown an inhibition of morphological changes (13). Similarly, some reports suggest that inhibiting the Raf-MAPK pathways blocks ANP transcription (1114) while other have seen little effects (15).

The activity of the Rho family of small GTPase appears in part to be regulated by ras proteins (16-18). Included in this family of proteins are the $21 \mathrm{kd}$ protein rhoA, cdc42, and rac1. Studies in other cell types, particularly Swiss 3T3 cells, have demonstrated a crucial role for this family of proteins in control of cellular morphology $(16,19,20)$. Given that these proteins appear to function downstream of ras, the Rho family of small GTP-binding proteins represent potential candidate molecules for controlling a ras-regulated but Raf-independent pathway leading to myocyte hypertrophy. This contention is

1. Abbreviations used in this paper: ANP, atrial natriuretic peptide; JNK, c-Jun amino-terminal peptide; MAPK, mitogen-activated protein kinase; MOI, multiplicity of infection. 
also supported by the observation that in other cell types, distinct effector pathways are involved in the ability of ras to regulate the cytoskeleton and activate MAPK (21).

Recent studies support a potential role for the Rho GTPases in hypertrophic signal transduction. In particular, rhoA was demonstrated to regulate in part cardiac myocyte ANP levels (22). In contrast, in a subsequent study using C3 transferase, a specific biochemical inhibitor of rhoA, no effect was observed on actin organization or sarcomere formation induced by phenylephrine (23). Although the later results argue against a role for rhoA in regulating phenylephrine stimulated morphological hypertrophy, it does not, however, exclude the participation of other Rho family members in this process.

To pursue the potential role of other Rho family members, this study examined the role of rac1 in cardiac hypertrophy. We have used recombinant adenoviruses as a method of gene transfer. Such methodology avoids the extremely low transfection rates of past strategies and allows for direct biochemical measurements of hypertrophy on an entire population of nondividing neonatal cardiac myocytes. Using such a strategy, we demonstrate here a requirement for rac1 in hypertrophic signaling.

\section{Methods}

Cell culture. Neonatal ventricular myocytes were harvested from the hearts of 2-d-old Sprague-Dawley rat pups and isolated through overnight cold trypsin digestion in calcium and magnesium-free HBSS followed by warm collagenase digestion in Leibovitz's L-15 media (Worthington Biochemical, Freehold, NJ). Myocytes were released and dispersed from their surrounding connective tissue through 40 triturations and the resultant cellular suspension was filtered through $70-\mu \mathrm{m}$ strainer to remove most of the cellular debris. The cells were pelleted by low-speed centrifugation and resuspended in plating media (DME-F12: DME/Hams F-12, 1:1 with 15 mM Hepes pH 7.5; 2 $\mathrm{mg} /$ liter BSA, $10 \mathrm{mg} /$ liter insulin, $5.5 \mathrm{mg} /$ liter transferrin, $5 \mu \mathrm{g} /$ liter selenium; $2 \mathrm{mg} / \mathrm{liter}$ ethanolamine, 10,000 U/ml penicillin, and 10,000 $\mu \mathrm{g} /$ $\mathrm{ml}$ streptomycin) supplemented with $5 \%$ horse serum (Gibco Laboratories, Gaithersburg, MD) for the first $24 \mathrm{~h}$. The mixture of myocytes and nonmyocytes (fibroblasts) was purified by two differential preplatings for $30 \mathrm{~min}$. Remaining cells were $>90 \%$ myocytes as determined by immunohistochemical staining. Cells were plated on laminin-coated plates at a density of $4 \times 10^{4} \mathrm{cells} / \mathrm{cm}^{2} .24 \mathrm{~h}$ after plating, the media were exchanged for serum-free DME-F12.

Adenoviruses. Two Ad5 serotype E1-deleted control adenoviruses, Ad.dl312 (24), which lacks a transgene, and Ad.ßGal (25), which contains the Escherichia coli lacZ gene product, were used in this study and gave indistinguishable results. All infections were for $12 \mathrm{~h}$ and occurred $24 \mathrm{~h}$ after plating. Infections, unless stated other- wise, were performed at a multiplicity of infection (MOI) of 100 . Adenoviral stocks were prepared and titered on 293 cells and purified by double cesium chloride centrifugation (25). Assessment of gene transfer efficiency after Ad. $\beta$ Gal infection was as previously described (25).

An adenovirus encoding the myc-epitope tagged-dominant negative rac1 cDNA containing a substitution at position 17 (N17rac1) has been previously described (26). A similar strategy was used to construct an adenovirus encoding a constitutively active mutant of rac1 (Ad.V12rac1).

To construct an adenovirus encoding a form of Raf-1, we used the $\mathrm{NH}_{2}$-terminal domain (amino acids 1-149) of the protein. This region is sufficient to interact with ras but lacks the kinase domain $(27,28)$. The Raf-1 cDNA (1-149) was inserted into the adenoviral shuttle vector pAdCMVBH containing the cytomegalovirus immediate early promotor followed by a BamH1 site and an in-frame nine-amino acid (HA) epitope tag derived from the HA1 protein of influenza. The recombinant adenovirus Ad.Raf (1-149) was generated by cotransfection of 293 cells using the adenoviral shuttle vector containing Raf (1149) and Cla1 cut adenoviral DNA as previously described (29).

Expression of the epitope-tagged form of Raf (1-149), N17rac1, and V12rac1 was assessed by Western blotting using $20 \mu \mathrm{g}$ of myocardial protein lysate along with HA and $m y c$-specific antibodies (9E10, Santa Cruz; $2 \mu \mathrm{g} / \mathrm{ml}$ ) and enhanced chemiluminescence (26). Similarly, total rac levels were determined using a rac-specific antibody (C-11, Santa Cruz; $2 \mu \mathrm{g} / \mathrm{ml}$ ).

Surface area and actin staining. After $12 \mathrm{~h}$ of adenoviral infection, cells were exposed to $48 \mathrm{~h}$ of acute stimulation with $500 \mu \mathrm{M}$ phenylephrine (Sigma Chemical Co., St. Louis, MO). For cell surface area measurements, myocytes were visualized by staining with Diff Quick (Dade Diagnostics, Aguada, PR) and surface areas determined by computer-assisted planimetry (Advanced Imaging Concepts, Princeton, NJ) by an observer blinded to experimental conditions. For each condition, surface area was measured from at least 30 individual cells. To visualize filamentous actin cytoskeleton, cells on chamber slides were fixed and permeabilized ( $0.1 \%$ Triton X-100 for $5 \mathrm{~min})$ and then incubated for $1 \mathrm{~h}$ in the dark with fluorescein-conjugated phalloidin (Molecular Probes, Eugene, OR). After rinsing, coverslips were mounted using Vectashield (Vector Laboratories). Sarcomeric actin reorganization was monitored on a fluorescence microscope (63X; Carl Zeiss, Inc., Thornwood, NY) and images recorded on color slide film. To confirm that only myocytes were analyzed, permeabilized cells were also incubated with an antibody to sarcomeric myosin (MF-20), followed by an Alexa Red-conjugated goat anti-mouse secondary antibody (Molecular Probes). Where indicated, cells were pretreated with the MEK inhibitor PD98059 (Alexis Pharmaceuticals, San Diego, CA) for 30 min before phenylepherine stimulation.

ANP assay. Quantification of immunoreactive atrial natriuretic peptide secreted by the myocytes was performed by ${ }^{125}$-RIA analysis (Biotrak ANP Radioimmunoassay System; Amersham Chemical Corp., Arlington Heights, IL) according to the manufacturer's recommendation. To determine cell-associated ANP, cells were rinsed
A

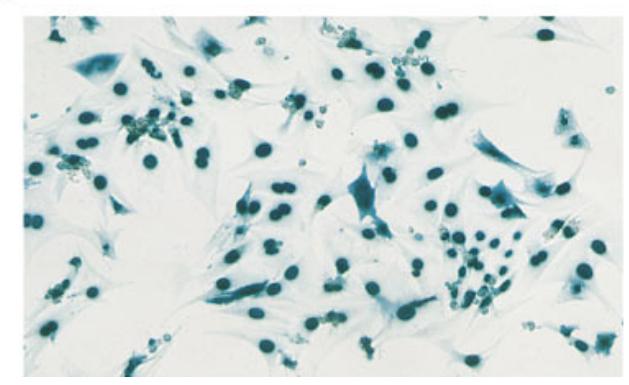

B

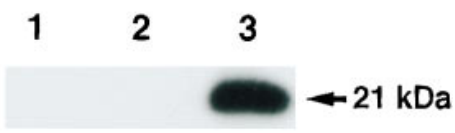

Figure 1. Analysis of adenoviral-mediated gene transfer expression in primary neonatal ventricular myocytes. ( $A$ ) Representative field after histochemical staining (X-GAL) of myocytes infected $48 \mathrm{~h}$ previously with Ad. $\beta \mathrm{Gal}$ (100 MOI) encoding a nuclear-localizing $E$. coli LacZ gene product. $(B)$ Western blot analysis performed using a myc-specific antibody demonstrating the expression of the $21-\mathrm{kD}$ epitopetagged form of rac1 using lysates obtained from uninfected (lane 1), Ad. BGALinfected (lane 2), or Ad.V12rac1-infected cells (lane 3 ). 
twice and subjected to five freeze-thaw cycles on dry ice. An aliquot of the lysate was taken and the amount of ANP quantitated as above.

MAPK assay. Myocytes were stimulated with phenylephrine for 20 min before harvest. After ligand exposure, cells were quickly washed twice in PBS supplemented with orthovanadate. Cells were then lysed at $4^{\circ} \mathrm{C}$ in buffer A (20 mM Hepes, pH 7.5, $10 \mathrm{mM}$ EGTA, $40 \mathrm{mM} \beta$-glycerophosphate, $1 \% \mathrm{NP}-40,2.5 \mathrm{mM} \mathrm{MgCl}_{2}, 2 \mathrm{mM}$ orthovanadate, $1 \mathrm{mM}$ DTT, $1 \mathrm{mM}$ PMSF, $20 \mu \mathrm{g} / \mathrm{ml}$ aprotinin, and $20 \mu \mathrm{g} / \mathrm{ml}$ leupeptin). After a brief 20-min spin $(14,000 \mathrm{~g}), 75 \mu \mathrm{g}$ of supernatant was immunoprecipitated with $5 \mu$ of an anti-MAPK antibody preconjugated to agarose beads (Santa Cruz). Immunocomplexes were washed three times with buffer B (PBS supplemented with $1 \%$ NP40, $2 \mathrm{mM}$ vanadate), once with buffer C (100 mM Tris $\mathrm{pH} 7.5,0.5 \mathrm{M}$ $\mathrm{LiCl})$, once in kinase buffer (12.5 mM MOPS, pH 7.5, $12.5 \mathrm{mM}$ $\beta$-glycerophosphate, $7.5 \mathrm{mM} \mathrm{MgCl} 2,0.5 \mathrm{mM}$ EGTA, $0.5 \mathrm{mM}$ sodium fluoride, $0.5 \mathrm{mM}$ orthovanadate) and then resuspended in $30 \mu \mathrm{l}$ of kinase buffer, supplemented with $1 \mu \mathrm{Ci}\left[\gamma^{32} \mathrm{P}\right] \mathrm{ATP}, 20 \mu \mathrm{M}$ unlabeled ATP, and $1.5 \mathrm{mg} / \mathrm{ml}$ of myelin basic protein substrate (Sigma Chemical Co.). After $20 \mathrm{~min}$ at $30^{\circ} \mathrm{C}$ the reaction was terminated by the addition of $10 \mu \mathrm{l}$ of $5 \times$ Laemmli buffer and incubated at $95^{\circ} \mathrm{C}$ for $5 \mathrm{~min}$. The products were visualized by electrophoresis on a SDS-polyacrylamide gel.

Leucine incorporation. For assessment of protein synthesis, 1 $\mu \mathrm{Ci} / \mathrm{ml}$ of $\left[{ }^{3} \mathrm{H}\right]$ leucine (Amersham Chemical Corp.) was added to each well $12 \mathrm{~h}$ after viral infection. Where indicated, phenylephrine was added simultaneously with labeled leucine. $24 \mathrm{~h}$ later, the $\left[{ }^{3} \mathrm{H}\right]$ leucine-containing media was aspirated and the cells were washed twice with PBS, trypsinized, and resuspended on ice for $1 \mathrm{~h}$ with TCA. The TCA precipitate was pelleted at $14,000 \mathrm{~g}\left(4^{\circ} \mathrm{C}\right)$ for 5 min, washed with $1.0 \mathrm{ml}$ PBS, and resuspended in $0.1 \mathrm{~N} \mathrm{NaOH}$ for 90 min. An aliquot was dissolved in scintillation cocktail and stored overnight in the dark $\left(4^{\circ} \mathrm{C}\right)$ to reduce chemiluminescence.

\section{Results}

Infection of neonatal rat ventricular myocytes with recombinant adenoviruses resulted in successful gene transfer in a high percentage of cells. As demonstrated in Fig. $1 A$, infection with an adenovirus encoding for a marker gene product (nuclear-localizing $\beta$-galactosidase) resulted in $>90 \%$ of cells exhibiting histochemical staining consistent with successful gene transfer. Similarly, Western blot analysis of protein lysates from adenoviral-infected myocytes readily detected expression of the epitope-tagged activated form of rac-1 (V12rac1) (Fig. 1B).

To understand the role of rac1 in hypertrophic signal transduction, we first infected myocytes with an adenovirus encoding a constitutively active isoform of rac-1 (Ad.V12rac1). Morphological analysis revealed that under basal conditions, both uninfected cells and cells infected with a control adenovirus (Ad.dl312) revealed a reticular, actin organization that lacked sarcomeric formation (Fig. 2, $A$ and $C$ ). In contrast, Ad.V12rac1 infection dramatically increased the numbers of actin filaments per cell. More importantly, V12rac1 expression
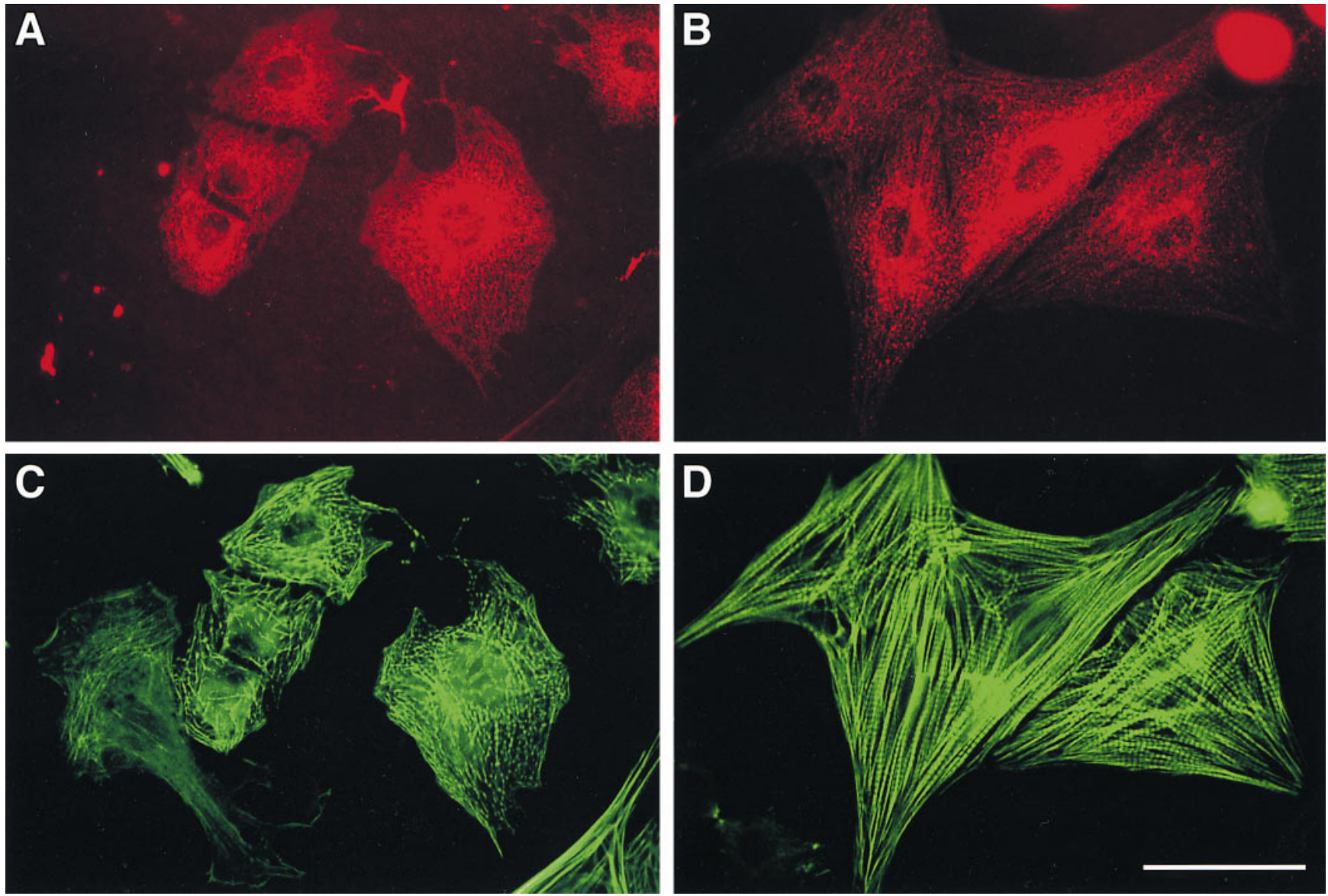

Figure 2. Effects of Ad.V12rac1 expression on sarcomeric organization. Morphology of representative myocytes $48 \mathrm{~h}$ after infection with $(A$ and $C)$ a control adenovirus (Ad.d1312) or $(B$ and $D)$ Ad.V12rac1. Top: $(A$ and $B)$ Cells were analyzed by indirect immunofluorescence with a sarcomeric myosin-specific antibody (MF-20). ( $C$ and $D)$ Actin filaments were visualized by using fluorescein-conjugated phallodin. Bar at lower right corner, $50 \mu \mathrm{m} . \times 630$. 
was sufficient to induce a heavily striated appearance, reflecting the reorganization of the actin cytoskeleton into sarcomeric structures (Fig. 2, $B$ and $D$ ).

To further characterize the ability of the constitutitively active rac1 to elicit morphological hypertrophy we measured cell surface areas. As depicted in Fig. 3, Ad.V12rac1 infection produced a significant increase in cell surface area when compared to uninfected myocytes or to myocytes infected with a control adenovirus (Ad.dl312). The increase in cell surface area was in proportion to the MOI, and hence the level of expression, of V12rac1. In an attempt to further correlate our morphological observations with other established markers of cellular hypertrophy, we also measured levels of ANP secreted into the cell culture media. Such direct biochemical assays were feasible because of the high level of gene transfer efficiencies achieved even in nondividing cells with recombinant adenoviruses. Compared with cells infected with a control adenovirus (Ad.dl312), infection with Ad.V12rac1 resulted in an approximate twofold increase in secreted immunoreactive ANP (Fig. $4 A$ ). This increase in the level of ANP in the media was unlikely to be solely a result of an increase in the rate of secretion of stored ANP, since a similar magnitude increase was also demonstrated for intracellular ANP levels (Fig. $4 B$ ).

Because the morphological alterations induced by Ad.V12rac1 resembled the hypertrophic response produced after the administration of pharmacologic ligands, we next sought to determine the role of rac1 in the regulation of phenylephrine-induced morphological hypertrophy. Myocytes were infected with an adenovirus encoding a dominant negative form (N17rac1) of rac1. As shown in Fig. 5, levels of expression of N17rac1 were proportional to the MOI used. We observed similar levels of rac expression following infection

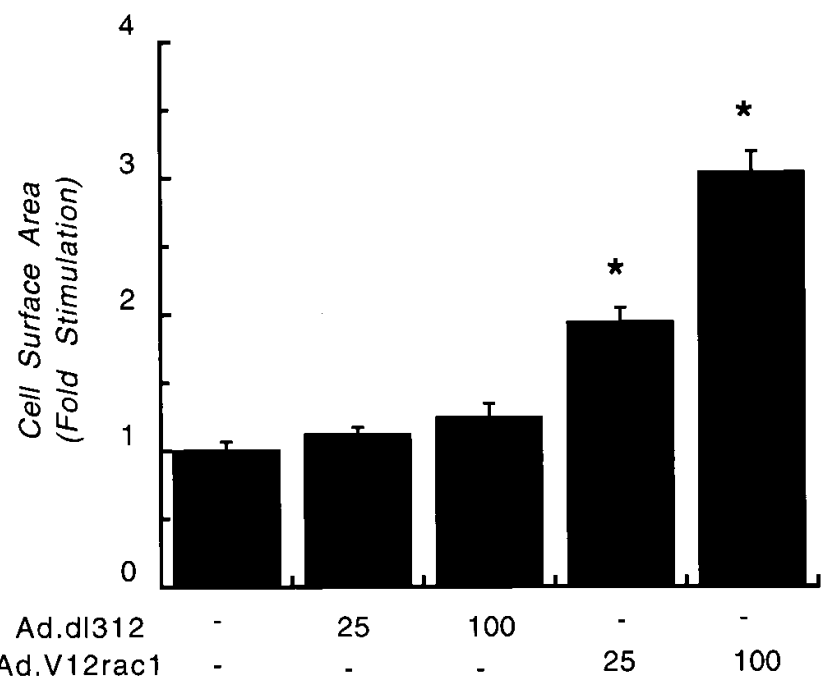

Figure 3. Effects of Ad.V12rac1 infection on myocyte cell surface area. The surface area (mean \pm SEM) of cells infected at an MOI of 25 or 100 with either a control adenovirus (Ad.dl312) or with Ad.V12rac1. Areas (determined initially in units of squared pixels) were quantitated by computer-assisted planimetery by a blinded observer and are the result of at least 30 determinations per condition, from one of three similar experiments. Asterisks denote significant differences $(P<0.05)$ from control values, evaluated first by one-way ANOVA, followed post-hoc by Fisher's protected least significant difference.
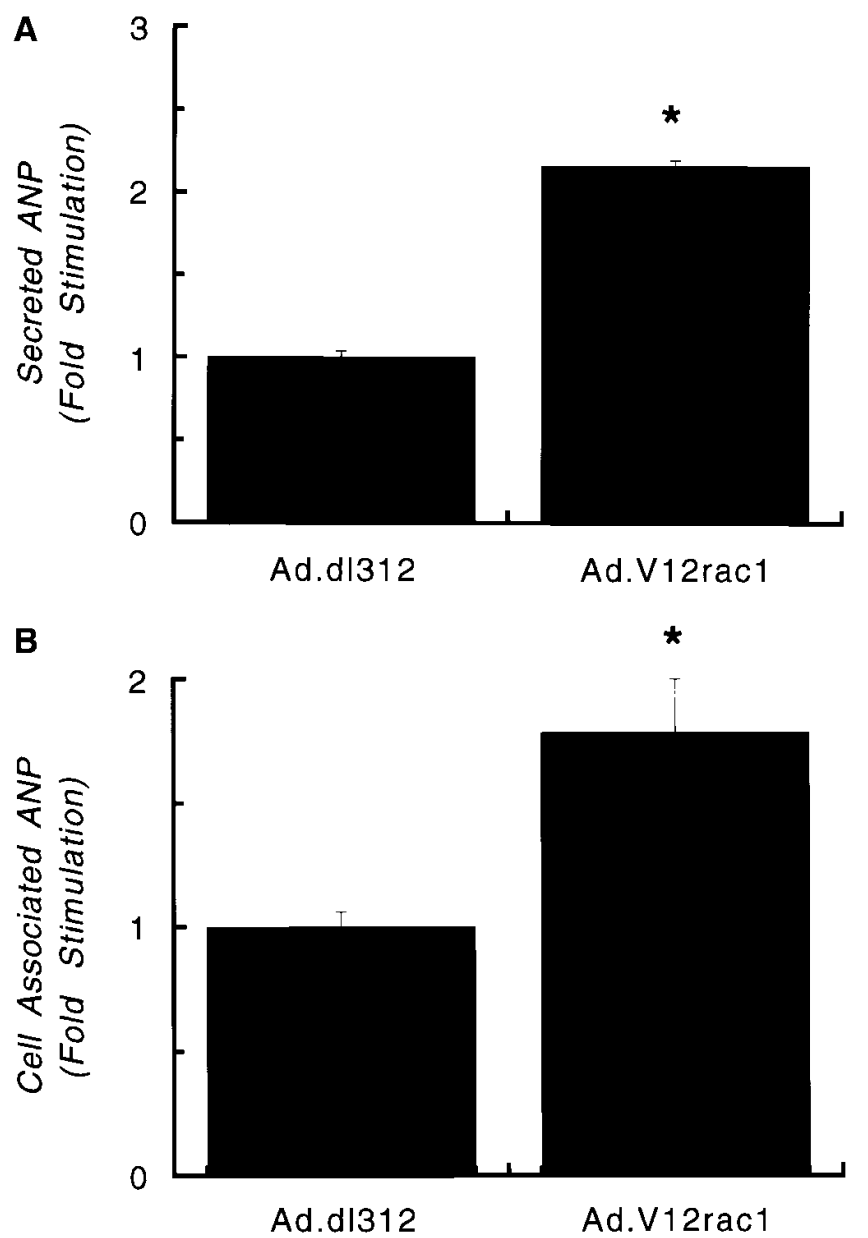

Figure 4. Expression of V12rac1 regulates the level of immunoreactive ANP in neonatal ventricular cardiomyocytes. $(A)$ Levels of ANP obtained from cell culture supernatants were determined by RIA. Values are expressed as the mean \pm SEM of duplicate measurements from each of three individual wells per treatment condition. Four additional experiments yielded similar results. Absolute levels of immunoreactive ANP obtained from a 48-h collection of $2.5 \times 10^{4}$ control infected cells was $\sim 5$ pmol. $(B)$ Level of ANP determined from corresponding cell lysate. Asterisks denote significant differences from control values, as evaluated by Student's $t$ test $(P<0.01$ for $A$, and $P<0.05$ for $B)$.

with either Ad.N17rac1 or Ad.V12rac1 (data not shown). Using an MOI of 100, infection with Ad.N17rac1 led to an approximate two- to threefold increase in total rac levels (Fig. 5 $C$ ), suggesting that at this MOI, levels of the dominant negative isoform exceeded the level of wild-type rac1 protein.

We next studied the effects of N17rac1 expression on ligand-stimulated myocyte hypertrophy. As seen in Fig. 6, control infected cells responded to phenylephrine administration with an increase in both the number of actin filaments as well as the appearance of striated sarcomeric structures (Fig. 6 A). In contrast, the morphological appearance of phenylephrine stimulation was vastly different in myocytes expressing the dominant negative rac (N17rac1) isoform. In general, there was a significant decrease in the number of actin fibers (Fig. 6, $B$ and $C$ ). In addition, the remaining fibers were disorganized and fragmented, demonstrating varying levels of sarcomeric organization (striations). The disruption of morphological hy- 


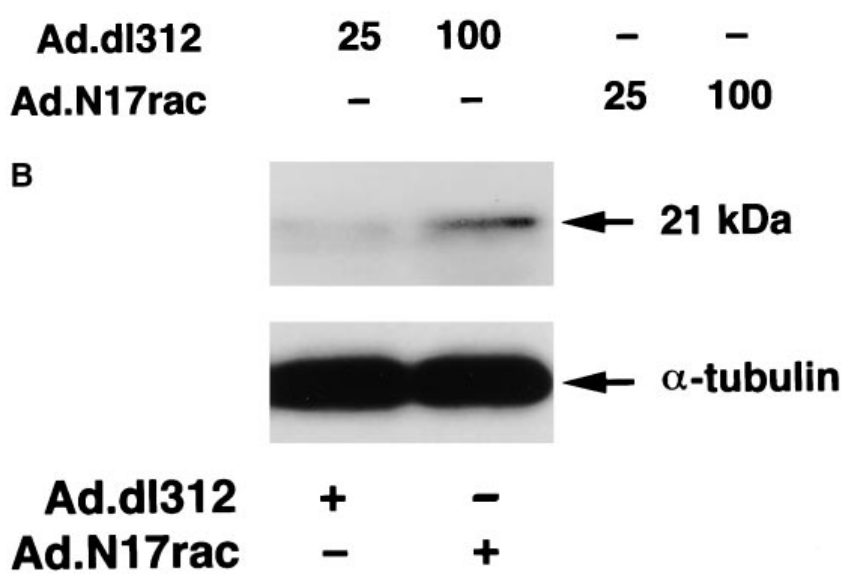

pertrophy caused by N17rac1 expression was proportional to the level of N17rac1 expression.

Previous experiments have demonstrated that expression of an activated ras gene product induced similar changes in cellular morphology to what we observed with V12rac1 expression (5). As such, our results are consistent with studies in other cell types which suggest that ras may function upstream of rac1 (16-18). Although ras proteins have a variety of downstream effectors (10), perhaps the best characterized is the ability of ras GTPases to regulate the activity of MAPK. We therefore sought to understand whether the activation of MAPK was essential for the morphological changes associated with hypertrophy.

Previous studies have demonstrated that phenylephrine stimulates MAPK activity $(12,15,22)$. As noted in Fig. $7 A$, expression of N17rac1 at a level (100 MOI) sufficient to disrupt the morphological response to phenylephrine (see Fig. $6 \mathrm{C}$ ), had no effect on the activation of MAPK. These results suggest that N17rac expression does not through a nonspecific or toxic effect inhibit all signaling pathways and argues that MAPK activation is not sufficient for the morphological changes induced by phenylephrine stimulation.

To further pursue the role of MAPK in morphological hypertrophy we overexpressed a truncated form of the $\mathrm{NH}_{2}$-terminal domain of Raf-1 (amino acids 1-149). This $\mathrm{NH}_{2}$-terminal domain is capable of stably binding to ras proteins and can therefore inhibit downstream ras-dependent signal transduction pathways $(27,28)$. Expression of Raf (1-149) was readily detected in lysates (Fig. 7 B). In contrast, however, to the expression of N17rac1, expression of this Raf isoform had no discernable effect on phenylephrine-stimulated morphological changes (Fig. $7 \mathrm{C}$ ).

Similar results were obtained when myocytes were treated with a pharmacological inhibitor of MEK, the kinase immediately upstream of MAPK. Treatment with the MEK-specific inhibitor PD98059, at a concentration previously demonstrated to inhibit ligand-stimulated MAPK activity in neonatal myocytes (23), did not result in any inhibition of the phenylephrineinduced morphological changes (Fig. 7 D). Taken together, these observations argue against a role for MAPK activation in phenylephrine-stimulated sarcomeric reorganization.
Figure 5. Levels of N17rac1 expression in cardiac myocytes. (A) Western blot for N17rac1 expression after infection at the indicated MOI. Protein expression was assessed with an antibody recognizing the $m y c$ epitope tag. (B) Total levels of rac expression after infection at 100 MOI with either Ad.dl312 or Ad.N17rac1. Blots were probed with a rac-specific antibody (top) or a tubulin antibody (bottom) to confirm equal protein loading.

Finally, we measured the effect of V12rac1 and N17rac1 expression on new protein synthesis. As seen in Fig. 8, consistent with the ability of V12rac1 to increase cell surface area, expression of this rac isoform resulted in an increase in leucine incorporation. Similarly, phenylephrine stimulation resulted in an approximate twofold increase in new protein synthesis. Although N17rac1 had little effect on basal leucine incorporation, levels of ligand-stimulated protein synthesis were inhibited in proportion to the level of N17rac1 expression.

\section{Discussion}

We demonstrate a role for the small GTPase rac1 in the cardiac myocyte hypertrophic response. Expression of constitutively activated form of rac1 leads to sarcomeric reorganization, an increase in ANP secretion, and a stimulation of new protein synthesis. In contrast, expression of N17rac1 blocks the ability of phenylephrine to reorganize the cytoskeleton as well as to stimulate leucine incorporation. Moreover, the morphological effects of rac appeared to be independent of MAPK activation. Our results, therefore, suggest a critical role for racdependent signal transduction in both the biochemical and morphological response to hypertrophy.

In other cell types, the family of Rho GTPases has been demonstrated to regulate downstream kinases including p38 kinase and the c-Jun amino-terminal kinase (JNK) (30-32). Studies suggests that in myoctes these kinases are activated by hypertrophic stimuli and may mediate the hypertrophic response (33-39). In particular, very recent evidence suggests that the activation of p38 kinase may be critical in mediating the hypertrophic response $(36,37,39)$. The role of JNK is less clear with some evidence suggesting that it may mediate hypertrophy $(38,40)$, while other studies suggest that JNK activation may inhibit the hypertrophic response (39). In addition, the balance of JNK and p38 as well as the p38 isoform that is activated appear to be important elements in determining the myocyte response $(37,39)$.

It should be noted that although V12rac1 expression was sufficient to induce morphological hypertrophy, N17rac1 did not completely inhibit all phenylephrine-stimulated cytoskeletal changes. Indeed, although N17rac1 expressing cells showed 

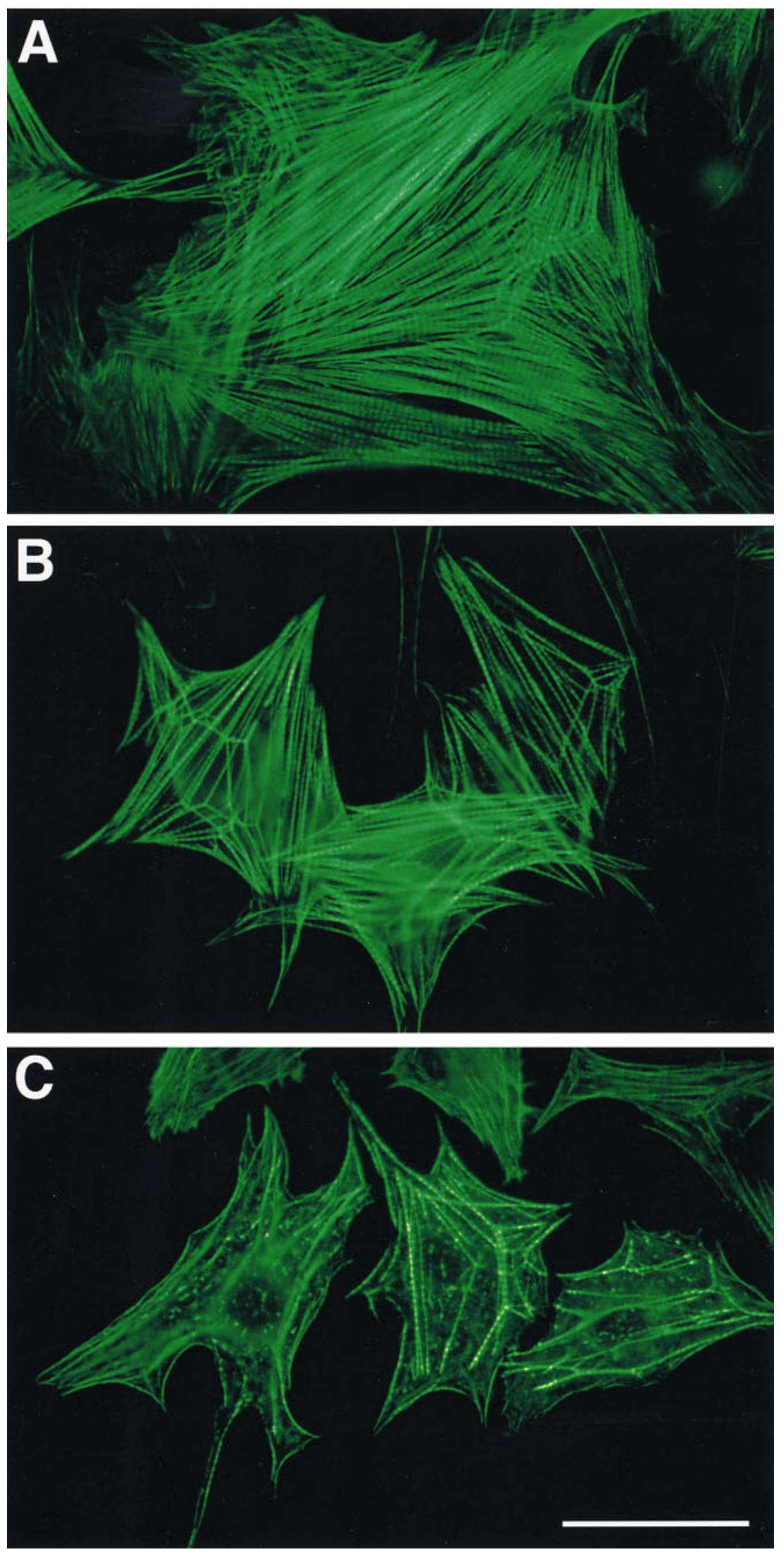

Figure 6. Effects of Ad.N17rac1 expression on sarcomeric organization. Morphological appearance of cells $48 \mathrm{~h}$ after phenylephrine stimulation in $(A)$ Ad.dl312-infected cells or Ad.N17rac1-infected myocytes at either 25 MOI $(B)$ or 100 MOI $(C)$. Actin filaments were visualized by using fluorescein-conjugated phallodin. $\times 630$. 

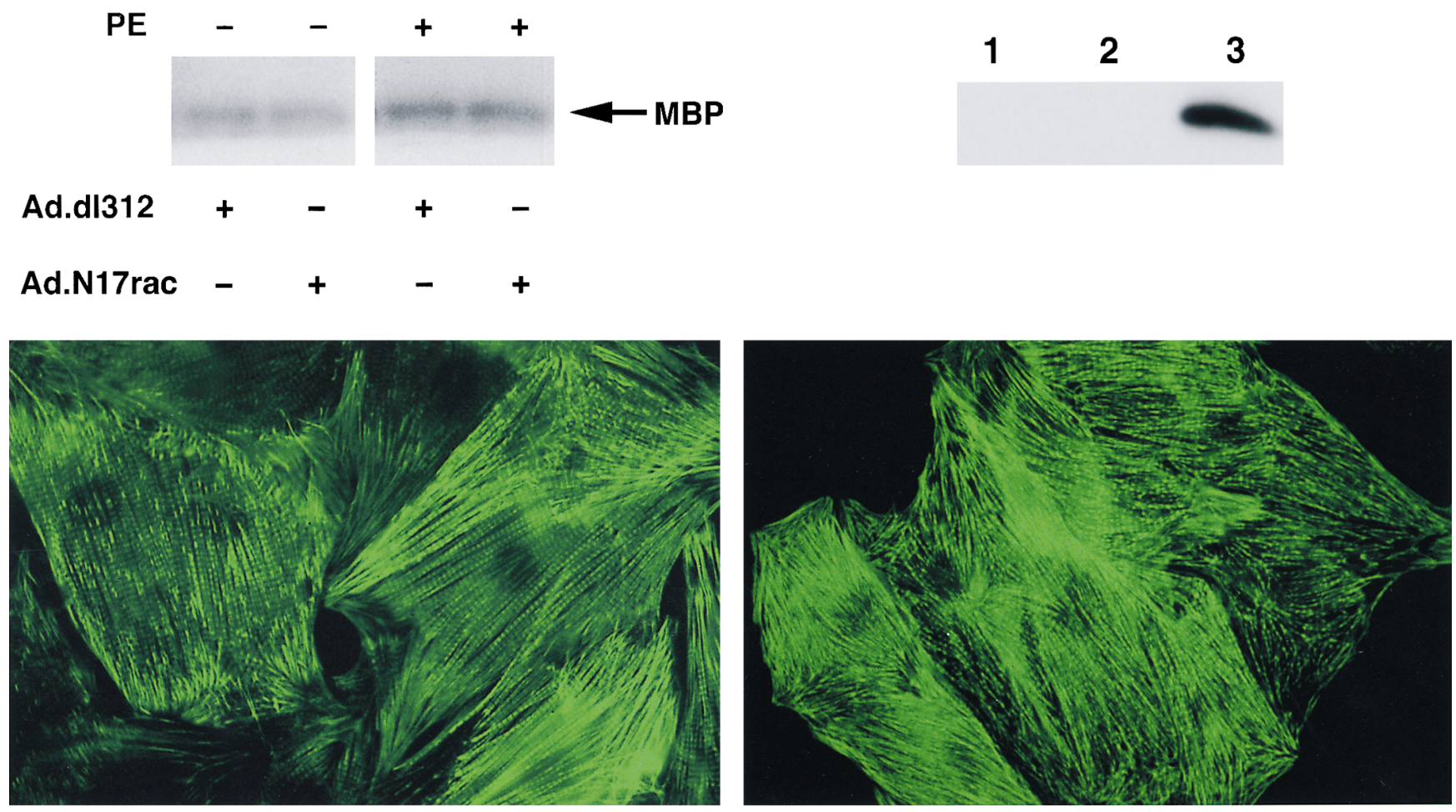

C

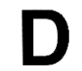

Figure 7. Sarcomeric organization and the activation of MAPK. (A) MAPK activity, using an in vitro kinase assay with myelin basic protein $(M B P)$ as a substrate, for cells infected at a 100 MOI with either Ad.dl312 or Ad.N17rac1. Where indicated, cells were stimulated with phenylephrine $(P E)$ for 20 min before harvest. $(B)$ Western blot analysis performed using a HA-specific antibody detects the expression of the epitope tagged truncated Raf isoform in lysates obtained from uninfected (lane 1), Ad.dl312-infected (lane 2), or Ad.Raf(1-149)-infected cells (lane 3). (C) Sarcomeric organization in cell infected with Ad.Raf(1-149) and stimulated with phenylephrine. (D) Morphology of cells pretreated with the MEK inhibitor PD98059 $(10 \mu \mathrm{M})$ and stimulated with phenylephrine. Actin filaments were visualized by using fluorescein-conjugated phalloidin. $\times 630$.

fewer and shorter actin filaments, the filaments that were present demonstrated some degree of sarcomere formation. This most likely was because N17rac1 was not expressed in large enough amounts to entirely block all rac-dependent signaling. Indeed, Western blot analysis suggests that the N17rac isoform was expressed at roughly two- to threefold higher levels compared with endogenous rac1. As opposed to constitutively active forms, dominant negative isoforms of small GTPases are able to function in a dominant inhibitory fashion by competing for a limited pool of guanine nucleotide exchange factors. As such, it is not unreasonable to expect that at the same level of expression, V12rac1 could fully induce morphological hypertrophy, while N17rac1 would not be able to totally inhibit all the phenylephrine-induced hypertrophic changes.

It is also possible that V12rac1 may cause the secretion of an autocrine or paracrine factor which in turn, induces hypertrophy. Such a possibility is supported by the recent observation that microinjection of an activated rac1 induces $\mathrm{NF}-\kappa \mathrm{B}$ activation in not only the injected cell but also in the neighboring, noninjected cell (41). In our initial experiments treating myocytes with conditioned supernatants obtained from V12rac1-infected myocytes, we observed, however, no evi- dence for a soluble, rac-induced hypertrophy factor (unpublished observations).

Previous studies have placed rac1 downstream of ras in many pathways involving the cytoskeleton, growth, and transformation (16-18). The precise mechanism by which ras can activate rac1 is unknown. However, ras has been shown to directly bind to PI-3 kinase (42-44), which in turn, has been demonstrated to activate $\operatorname{rac} 1(45,46)$. Because previous studies have demonstrated a role for ras in cardiac hypertrophy both in vitro and in vivo $(5,47)$, the significance of this study is to further delineate the relevant ras-dependent signaling pathways. As noted previously, ras can also stimulate pathways involving Raf, mitogen activated protein/ERK kinase (MEK), and MAPK. The importance of this ras-regulated pathway in cardiac hypertrophy has been the subject of intensive and as noted, conflicting studies in the past (11-15). Our results suggest that the morphological aspects of hypertrophy most likely proceed through a rac-dependent but Raf-independent pathway.

Our results with N17rac1 expression imply a role for wildtype rac1 in phenylephrine-stimulated pathways. We have not, however, demonstrated by direct evidence that endogenous rac1 is stimulated by ligands. Although in a variety of cell types, stimulated by a host of ligands, it has been possible to 


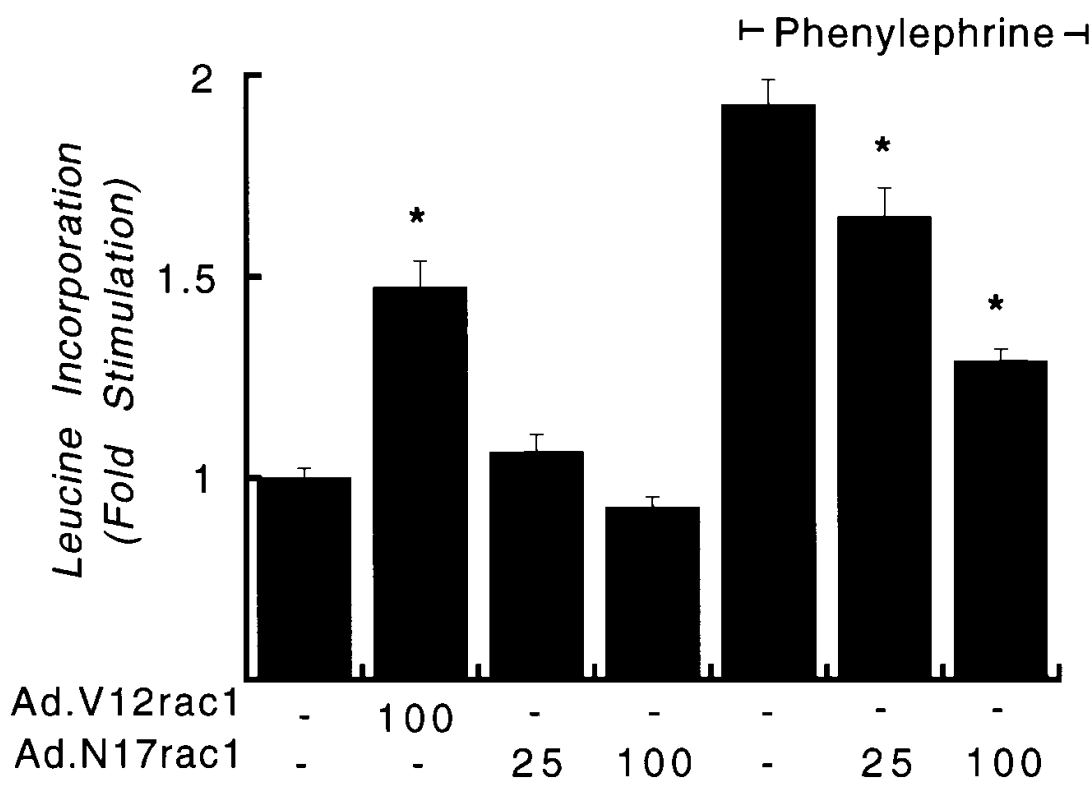

Figure 8. The regulation of new protein synthesis by rac1. Myocytes were infected with the indicated MOI of Ad.V12rac1 or Ad.N17rac1. Levels of leucine incorporation were determined under basal conditions or $24 \mathrm{~h}$ after phenylephrine stimulation. Results (mean \pm SEM) are from six determinations per treatment condition and are from one of two similar experiments. demonstrate an increase in GTP loading of ras proteins, similar assays with rac1 have been extremely difficult to perform (48). Although in myocytes the immediate downstream effectors of rac1 are unknown, in other cell types a variety of rac targets have been identified (49). Using similar approaches to what we have described for rac1, adenoviral-mediated delivery of these gene products, should allow for a further direct characterization of the hypertrophic signaling pathway.

\section{Acknowledgments}

The authors gratefully acknowledge Mr. Ricardo Dreyfuss for his assistance in the photomicroscopy of the cardiac myocytes.

\section{References}

1. Levy, D., R.J. Garrison, D.D. Savage, W.B. Kannel, and W.P. Castelli. 1988. Echocardiographically detected left ventricular hypertrophy: prevalence and risk factors: The Framingham Heart Study. Ann. Intern. Med. 108:7-13.

2. Levy, D., R.J. Garrison, D.D. Savage, W.B. Kannel, and W.P. Castelli. 1990. Prognostic implications of echocardiographically determined left ventricular mass in The Framingham Heart Study. N. Eng. J. Med. 322:1561-1566.

3. Bogoyevitch, M.A. and P.H. Sugden. 1996. The role of protein kinases in adaptational growth of the heart. Int. J. Biochem. Cell Biol. 28:1-12.

4. Lembo, G., J.J. Hunter, and K.R. Chien. 1995. Signaling pathways for cardiac growth and hypertrophy: recent advances and prospects for growth factor therapy. Ann. NY Acad. Sci. 752:115-127.

5. Thorburn, A., J. Thorburn, S.-Y. Chen, S. Powers, H.E. Shubeita, J.R. Feramisco, and K.R. Chien. 1993. HRas-dependent pathways can activate morphological and genetic markers of cardiac muscle cell hypertrophy. J. Biol. Chem. 268:2244-2249.

6. Thorburn, A. 1994. Ras activity is required for phenylephrine-induced activation of mitogen-activated protein kinase in cardiac muscle cells. Biochem. Biophys. Res. Commun. 205:1417-1422.

7. Sadoshima, J., and S. Izumo. 1996. The heterotrimeric $\mathrm{G}_{\mathrm{q}}$ protein-coupled angiotensin II receptor activates p21 ras via the tyrosine kinase-Shc-Grb2-Sos pathway in cardiac myocytes. EMBO (Eur. Mol. Biol. Organ.) J. 15:775-787.

8. Warne, P.H., P.R. Vician, and J. Downward. 1993. Direct interaction of Ras and the amino-terminal region of Raf-1 in vitro. Nature. 364:352-355.

9. Zhang, X., J. Settleman, J.M. Kyriakis, E. Takeuchi-Suzuki, S.J. Elledge, M.S. Marshall, J.T. Bruder, U.R. Rapp, and J. Avruch. 1993. Normal and oncogenic $\mathrm{p} 21$ ras proteins bind to the amino-terminal regulatory domain of c-Raf-1. Nature. 364:308-313.

10. Marshall, C.J. Ras effectors. 1996. Curr. Op. Cell Biol. 8:197-204.

11. Thorburn, J., J.A. Frost, and A. Thorburn. 1994. Mitogen-activated protein kinases mediate changes in gene expression, but not cytoskeletal organiza- tion associated with cardiac muscle cell hypertrophy. J. Cell Biol. 126:15651572.

12. Thorburn, J., M. McMahon, and A. Thorburn. 1994. Raf-1 kinase activity is necessary and sufficient for gene expression changes but not sufficient for cellular morphology changes associated with cardiac myocyte hypertrophy. $J$. Biol. Chem. 269:30580-30586.

13. Glennon, P.E., S. Kaddoura, E.M. Sale, G.J. Sale, S.J. Fuller, and P.H. Sugden. 1996. Depletion of mitogen-activated protein kinase using an antisense oligodeoxynucleotide approach down regulates the phenylephrine-induced hypertrophic response in rat cardiac myocytes. Circ. Res. 78:954-961.

14. Gillespie-Brown, J., S.J. Fuller, M.A. Bogoyevitch, S. Cowley, and P.H. Sugden. 1995. The mitogen-activated protein kinase MEK1 stimulates a pattern of gene expression typical of the hypertrophic phenotype in rat ventricular cardiomyocytes. J. Biol. Chem. 270:28092-28096.

15. Post, G.R., D. Goldstein, D.J. Thuerauf, C.C. Glembotski, and J.H. Brown. 1996. Dissociation of p44 and p42 mitogen-activated protein kinase activation from receptor-induced hypertrophy in neonatal rat ventricular myocytes. J. Biol. Chem. 271:8452-8457.

16. Ridley, A.J., and A. Hall. 1992. The small GTP-binding protein rho regulates the assembly of focal adhesions and actin stress fibers in response to growth factors. Cell. 70:389-400.

17. Qiu, R.G., J. Chen, D. Kirn, F. McCormick, and M. Symons. 1995. An essential role for Rac in Ras transformation. Nature. 374:457-459.

18. Rodriguez-Viciana, P., P.H. Warne, A. Khwaja, B.M. Marte, D. Pappin, P. Das, M.D. Waterfield, A. Ridley, and J. Downward. 1997. Role of phosphoinositide 3-OH kinase in cell transformation and control of the actin cytoskeleton by Ras. Cell. 89:457-467.

19. Ridley, A.J., H.F. Paterson, C.L. Johnston, D. Dickmann, and A. Hall. 1992. The small GTP-binding protein rac regulates growth factor-induced membrane ruffling. Cell. 70:401-410.

20. Nobes, C.D., and A. Hall. 1995. Rho, Rac, and Cdc-42 GTPases regulate the assembly of multimolecular focal complexes associated with actin stress fibers, lamellipodia, and filopodia. Cell. 81:53-62.

21. Joneson, T., M.A. White, M.H. Wigler, and D. Bar-Sagi. 1996. Stimulation of membrane ruffling and MAP kinase activation by distinct effectors of ras. Science. 271:810-812.

22. Sah, V.P., M. Hoshijima, K.R. Chien, and J.H. Brown. 1996. Rho is required for $\mathrm{G} \alpha_{\mathrm{q}}$ and $\alpha_{1}$-andrenergic receptor signaling in cardiomyocytes. $J$. Biol. Chem. 271:31185-31190.

23. Thorburn, J., S. Xu, and A. Thorburn. 1997. MAP kinase- and Rhodependent signals interact to regulate gene expression but not actin morphology in cardiac muscle cells. EMBO (Eur. Mol. Biol. Organ.) J. 16:1888-1900.

24. Jones, N., and T. Shenk. 1979. Isolation of adenovirus type 5 host range deletion mutants defective for transformation of rat embryo cells. Cell. 17:683-689.

25. Guzman, R.J., E.A. Hirschowitz, S.L. Brody, R.G. Crystal, S.E. Epstein, and T. Finkel. 1994. In vivo suppression of injury-induced vascular smooth muscle cell accumulation using adenovirus-mediated transfer of the herpes simplex virus thymidine kinase gene. Proc. Natl. Acad. Sci. USA. 91:10732-10736.

26. Sulciner, D., K. Irani, Z.X. Yu, V.J. Ferrans, P. Goldshmidt-Clermont, and T. Finkel. 1996. rac1 regulates a cytokine-stimulated, redox-dependent pathway necessary for NF-кB activation. Mol. Cell. Biol. 16:7115-7121.

27. Chuang, E., D. Barnard, L. Hettich, X.-F. Zhang, J. Avruch, and M.S. 
Marshall. 1994. Critical binding and regulatory interactions between Ras and Raf occur through a small, stable N-terminal domain of Raf and specific Ras effector residues. Mol. Cell. Biol. 14:5318-5325.

28. Emerson, S.D., V.S. Madison, R.E. Palermo, D.S. Waugh, J.E. Scheffler, K.-L. Tsao, S.E. Kiefer, S.P. Liv, and D.C. Fry. 1995. Solution structure of the Ras-binding domain of c-Raf-1 and identification of its Ras interaction surface. Biochemistry. 34:6911-6918.

29. Chinnadurai, G., S. Chinnadurai, and J. Brusca. 1979. Physical mapping of a large-plaque mutation of adenovirus type 2. J. Virol. 32:623-628.

30. Minden, A., A. Lin, F.X. Claret, A. Abo, and M. Karin. 1995. Selective activation of the JNK signaling cascade and c-Jun transcriptional activity by the small GTPases Rac and Cdc42Hs. Cell. 81:1147-1157.

31. Coso, O.A., M. Chiariello, J.C. Yu, H. Teramoto, P. Crespo, N. Xu, T. Miki, and J.S. Gutkind. 1995. The small GTP-binding proteins Rac1 and Cdc42 regulate the activity of the JNK/SAPK signaling pathway. Cell. 81:1137-1146.

32. Olson, M.F., A. Ashworth, and A. Hall. 1995. An essential role for Rho, Rac, and Cdc42 GTPases in cell cycle progression through $\mathrm{G}_{1}$. Science. 269: 1270-1272.

33. Bogoyevitch, M.A., A.J. Ketterman, and P.H. Sugden. 1995. Cellular stresses differentially activate c-Jun N-terminal protein kinases and extracellular signal-regulated protein kinases in cultured ventricular myocytes. J. Biol. Chem. 270:29710-29717.

34. Kudoh, S., I. Komuro, T. Mizuno, T. Yamazaki, Y. Zou, I. Shiojima, N. Takekoshi, and Y. Yazaki. 1997. Angiotensin II stimulates c-Jun $\mathrm{NH}_{2}$-terminal kinase in cultured cardiac myocytes of neonatal rats. Cir. Res. 80:139-146.

35. McDonough, P.M., D.S. Hanford, A.B. Sprenkle, N.R. Mellon, and C.C. Glembotski. 1997. Collaborative roles for c-Jun N-terminal kinases, c-Jun serum response factor, and $\mathrm{Sp} 1$ in calcium-regulated myocardial gene expression. J. Biol. Chem. 272:24046-24053.

36. Zechner, D., D.J. Thuerauf, D.S. Hanford, P.M. McDonough, and C.C. Glembotski. 1997. A role for the p38 mitogen-activated protein kinase pathway in myocardial cell growth, sarcomeric organization, and cardiac-specific gene expression. J. Cell Biol. 139:115-127.

37. Wang, Y.B., S.A. Huang, V.P. Sah, J. Ross, J.H. Brown, J.H. Han, and K.R. Chien. 1998. Cardiac muscle cell hypertrophy and apoptosis induced by distinct members of the p38 mitogen-activated protein kinase family. J. Biol. Chem. 273:2161-2168.

38. Wang, Y.B., B. Su, V.P. Sah, J.H. Brown, J.H. Han, and K.R. Chien.
1998. Cardiac hypertrophy induced by mitogen-activated protein kinase kinase 7, a specific activator for c-jun NH2-terminal kinase in ventricular muscle cells. J. Biol. Chem. 273:5423-5426.

39. Nemoto, S., Z. Sheng, and A. Lin. 1998. Opposing effects of jun kinase and p38 mitogen-activated protein kinases on cardiomyocyte hypertrophy. Mol. Cell. Biol. 18:3518-3526.

40. Ramirez, M.T., V.P. Sah, X.L. Zhao, J.J. Hunter, K.R. Chien, and J.H. Brown. 1997. The MEKK-JNK pathway is stimulated by $\alpha_{1}$-adrenergic receptor and Ras activation and is associated with in vitro and in vivo cardiac hypertrophy. J. Biol. Chem. 272:14057-14061.

41. Tapon, N., K. Nagata, N. Lamarache, and A. Hall. 1998. A new Rac target $\mathrm{POSH}$ is an $\mathrm{SH} 2$-containing scaffold protein involved in the JNK and NFkappa B signalling pathway. EMBO (Eur. Mol. Biol. Organ.) J. 17:1395-1404.

42. Rodriguez-Viciana, P., P.H. Warne, R. Dhand, B. Vanhaesebroeck, I

Gout, M.J. Fry, M.D. Waterfield, and J. Downward. 1994. Phosphatidylinositol3-OH kinase as a direct target of Ras. Nature. 370:527-532.

43. Kodaki, T., R. Woscholski, B. Hallberg, P. Rodriguez-Viciana, J. Downward, and P.J. Parker. 1994. The activation of phosphatidylinositol 3-kinase by Ras. Curr. Biol. 4:798-806.

44. Rodriguez-Viciana, P., P.H. Warne, R. Dhand, B. Vanhaesebroeck, M.D. Waterfield, and J. Downward. 1996. Activation of phosphoinositide 3-kinase by interaction with Ras and by point mutation. EMBO (Eur. Mol. Biol. Organ.) J. 15:2442-2451.

45. Hawkins, P.T., A. Eguinoa, R.G. Qiu, D. Stokoe, F.T. Cooke, R. Walters, S. Wennstrom, L. Claesson-Welsh, T. Evans, M. Symons, and L. Stephens. 1995. PDGF stimulates an increase in GTP-rac via activation of phosphoinositide 3-kinase. Curr. Biol. 5:393-403.

46. Kotani, K., K. Hara, K. Kotani, K. Uonezawa, and M. Kasuga. 1995. Phosphoinositide 3-kinase as an upstream regulator of the small GTP-binding protein Rac in the insulin signaling of membrane ruffling. Biochem. Biophys. Res. Comm. 208:985-990.

47. Hunter, J.J., N. Tanaka, H.A. Rockman, J. Ross, and K.R. Chien. 1995. Ventricular expression of MLC-2v-ras fusion gene induces cardiac hypertrophy and selective diastolic dysfunction in transgenic mice. J. Biol. Chem. 270:2317323178

48. Parker, P.J. 1995. PI 3-kinase puts GTP on the Rac. Curr. Biol. 5:577-579.

49. VanAelst, L., and C. D'Souza-Schorey. 1997. Rho GTPases and signaling networks. Genes \& Dev. 11:2295-2322. 